\title{
Changes in the Cortical Map of the Hand following Postnatal Ulnar and Radial Nerve Injury in Monkeys: Organization and Modification of Nerve Dominance Aggregates
}

\author{
John T. Wall, ${ }^{1}$ Michael F. Huerta, ${ }^{2}$ and Jon H. Kaas ${ }^{3}$ \\ 'Department of Anatomy, Medical College of Ohio, Toledo, Ohio 43699, 2Department of Biostructure and Function, \\ University of Connecticut Health Center, Farmington, Connecticut 06032, and ${ }^{3}$ Department of Psychology, Vanderbilt \\ University, Nashville, Tennessee 37240
}

\begin{abstract}
The ulnar and radial nerves to the hands of 12-31-d-old marmoset monkeys were transected and ligated, and the monkeys were subsequently reared for periods of 1.4-1.6 years with only median nerve innervation to the hand. Features of organization in the cortical area $3 b$ hand map were then assessed with neurophysiological mapping procedures, and compared to features in monkeys that had undergone either a normal postnatal development with three intact hand nerves, or an abnormal development with two intact nerves due to postnatal injury of the median nerve.

A systematic comparison of cortical organization in these monkeys led to three main findings. First, some features of organization show little or no change when monkeys are reared with one, two, or three hand nerves. These features include receptive field size and the overall size of the hand map. Second, other features are, in contrast, clearly altered in an injury-dependent manner. These features include cortical neuronal thresholds to light tactile stimuli, and the spatial location, size, shape, continuity, and somatotopic interfacing of representations of the parts of the hand. Finally, estimates of the peripheral innervation territories of the hand nerves, and of the corresponding distributions of cortical neurons activated by inputs from these territories, indicate that the normal hand map contains bandlike aggregates of neurons that are dominantly activated by inputs from each nerve. Postnatal nerve injuries alter the size of these nerve dominance aggregates.
\end{abstract}

The preceding study compared features of organization in the cortical hand maps of monkeys that had undergone postnatal rearing either with three normal nerves to the hand, or with two normal nerves and a transected and ligated median nerve (Wall et al., 1992). The results indicate that the cortical area $3 \mathrm{~b}$ hand map undergoes somatotopic reorganization after early injury of a hand nerve. In the visual system, postnatal enucleation leads to an enhanced cortical dominance of inputs from the intact eye and optic nerve (c.g., Hubel et al., 1977). Does cortical somatotopic reorganization after postnatal hand nerve injury re-

\footnotetext{
Received May 23, 1991; revised Mar. 26, 1992; accepted Mar. 31, 1992.

This work was supported by National Institutes of Health Grants NS 16446 and NS 21105 . We thank Judy Ives, Kelly Bergen, and Vincent Nepomuceno for their patient and skillful assistance. We are also very grateful to Bob Rhoades for comments on the manuscript.

Correspondence should be addressed to Dr. J. T. Wall at the above address. Copyright (C) 1992 Society for Neuroscience $0270-6474 / 92 / 123456-10 \$ 05.00 / 0$
}

flect a similar enhancement in nerve dominance? To address this question, this study assessed the cortical area $3 \mathrm{~b}$ hand maps of monkeys that were reared after postnatal transection and ligation of the ulnar and radial nerves. This injury left the hand innervated by only one nerve, the median nerve. By comparing the cortical organization in these monkeys to the organization in monkeys reared with either three or two intact nerves, it was possible to assess how the cortical dominance of a hand nerve is affected by the presence or absence of the other nerves.

\section{Materials and Methods}

Experiments were conducted on 14 marmoset monkeys (Callithrix jaccus) that were reared with one of three hand innervation conditions. Six monkeys developed with hands innervated by a normal median nerve, but with sectioned and ligated ulnar and radial nerves. The area $3 \mathrm{~b}$ hand cortex was completely mapped in four of these monkeys, whereas in the remaining two monkeys sampling was delimited to parts of the hand map. The data from these monkeys were compared to data from five monkeys reared with three normal nerves, and to data from three monkeys reared with two normal nerves following postnatal section and ligation of the median nerve. All monkeys were treated in accordance with the NIH Guide for the Care and Use of Laboratory Animals.

The procedures for nerve transection and ligation, neurophysiological mapping, and data analysis have been described previously (Wall et al., 1992). The ulnar and radial nerves were sectioned 12-31 d after birth, and the cortex was subsequently studied when the monkeys were 1.41.6 years old. These monkeys were adolescent or young adults by size and breeding age criteria for Callithrix.

\section{Results}

\section{Hand surfaces represented in the cortical map}

Hand innervation was evaluated by summing receptive fields in experiments in which the hand cortex was mapped completely. In contrast to the normal cortical representation of the complete hand (Wall et al., 1992), following ulnar-radial section inputs were lost from glabrous D5, the ulnar one-third to threefourths of the $\mathrm{PH}$ and $\mathrm{P} 4$ pads, and virtually all the hairy hand (Fig. 1A). The unrepresented skin reflects regions normally innervated by the radial and ulnar ncrves; conversely, the represented skin estimates the total innervation zone of the intact median nerve.

The innervation pattern after ulnar-radial section contrasts sharply with the pattern seen after median nerve section (Wall et al., 1992), and is predictable from the normal innervation territories of monkey hand nerves as defined from nerve recordings (e.g., Wall, 1990; J. T. Wall, unpublished observations). Taken together with the nerve recording results, it can be con- 

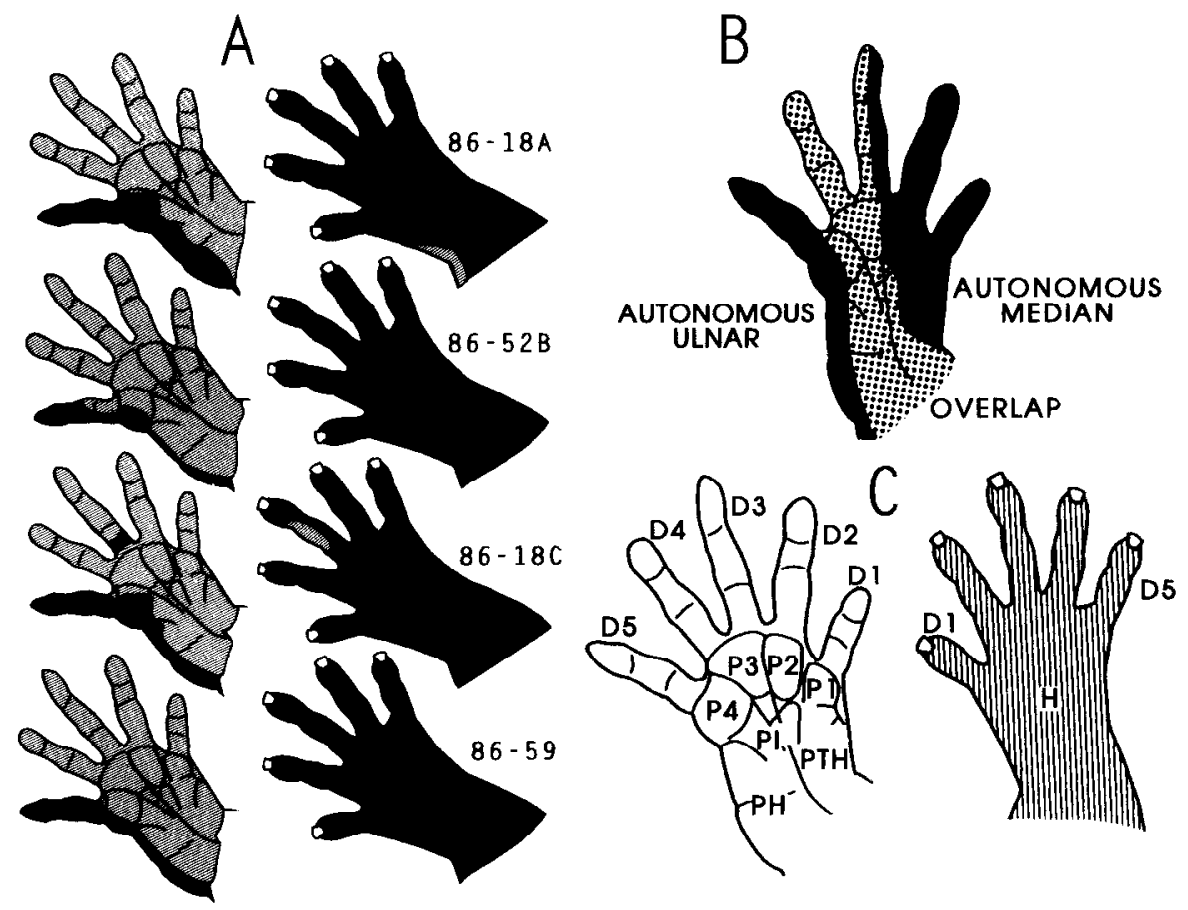

Figure 1. A, Innervated and denervated surfaces on the hands of four monkeys that had undergone postnatal section and ligation of the ulnar and radial nerves. Shading indicates innervated skin surfaces as estimated from the composite of all receptive fields recorded in the hand map. Black zones indicate denervated skin not represented in cortex. Note that with minor exceptions virtually all hairy skin, and glabrous skin on $D 5$ and the ulnar $\mathrm{PH}-\mathrm{P4}$ pads, was consistently denervated. The denervated skin provides an estimate of the combined autonomous innervation territories of the ulnar and radial nerves, whereas the innervated skin estimates the total low-threshold territory of the median nerve. $R$, Nerve innervation territories for the glabrous skin. The autonomous innervation territory of the median nerve is indicated in black to the right, the autonomous innervation territory of the ulnar nerve is indicated in black to the left, and intervening skin receiving overlapping innervation from both the median and ulnar nerves is indicated by stippling. These territories have been defined in nerve recording studies (Wall, 1990, unpublished observations) and were observed in part in the preceding nerve injury study (Wall et al., 1992). C, Abbreviations for parts of the hand: $P T H$, thenar pad; $P I-4$, pads $1-4 ; P H$, hypothenar pad; $P I$, insular pads; $D 1-D 5$, digits $1-5 ; H$, hairy hand between wrist and knuckles; $F Q$ (not shown), skin on the forelimb and adjacent body.

cluded that the glabrous hand innervation consists of three strips (Fig. $1 B$ ): a strip autonomously innervated by the median nerve (i.e., radial glabrous skin not represented after median scction), a strip autonomously innervated by the ulnar nerve (i.e., ulnar glabrous skin not represented after ulnar-radial section), and an intervening strip that receives overlapping innervation from the median and ulnar nerves (i.e., glabrous skin retaining representation after both median and ulnar-radial section). The identity of these nerve innervation territories was applied to the cortical assessments described below.

\section{Cortical activation reflected at single recording sites Responsiveness}

Following ulnar-radial section, cortical neurons at most (94\%) recording sites were responsive to cutaneous stimulation. Neurons at the remaining $6 \%$ of sites responded to harder tap stimuli, but it was unclear whether this activation involved highthreshold cutaneous and/or deep inputs. Thresholds for cutaneous responses did not differ across subdivisions of the innervated skin (Fig. $2 A$ ).

Cortical responsiveness differed from normal in that after ulnar-radial section (1) mean thresholds were lower for the autonomous median skin (e.g., Fig. $2 B$; compare "median" for normal vs ulnar-radial section; $t[61]=4.36, p=0.0001$ ), and overlap skin (e.g., Fig. $2 B$; compare "overlap" for normal vs. ulnar-radial section; $t[84]=3.60, p=0.0005$ ), and (2) neurons at a small percentage of cortical sites $(6 \%)$ were only responsive to high-threshold inputs, whereas normally all sites respond to low-threshold inputs. Compared to cortical responsiveness in monkcys rcarcd aftcr median section, ulnar-radial section resulted in lower mean thresholds for the overlap skin, the only skin where glabrous thresholds could be compared (e.g., Fig. $2 B$; compare "overlap" for median section vs. ulnar-radial section; $t[36]=3.57, p=0.001$ ). Both injuries resulted in a loss of low-threshold responsiveness at a similar small percentage of recording sites (median section $=8 \%$; ulnar-radial section $=$ $6 \%)$.

\section{Receptive field organization}

Size. Following ulnar-radial section, larger fields were typically proximal, and smaller fields more distal on the hand (Fig. 3 , top). The relative gradient in receptive field size with proximodistal location, and the absolute size of fields on a given hand location were similar in ulnar-radial section, median section, and normally reared monkeys (e.g., Fig. 3; see also Fig. 3 in Wall et al., 1992).

Continuity. Although most glabrous fields occupied a single, continuous skin 7one, "split" fields spanning adjacent but discontinuous digit skin comprised a mean of $15 \%$ of the glabrous fields recorded in ulnar-radial section monkeys. This incidence of split fields was modestly higher than that in median section $(2 \% ; t[5]=2.58, p=0.04)$ and normal $(5 \% ; t[5]=2.05, p=$ $0.09)$ monkeys.

Specificity. Following ulnar-radial section, most receptive fields 
Figure 2. A, Cortical response thresholds for glabrous inputs in monkeys reared after ulnar-radial section. Mean thresholds $( \pm$ SD) for the innervated glabrous skin and for different subregions of this skin are indicated by the corresponding patterns of stippling and hatching on the hands and histogram bars. Black regions indicate denervated skin where thresholds could not be measured. There were no significant differences in thresholds for different subregions that were compared including, for example, palm versus digit skin $(t[45]$ $=0.68, p=0.49$ ), and the overlap versus autonomous median skin strips $(t[45]=0.91, p=0.36)$. Threshold values are expressed in terms of markings on Semmes-Weinstein filaments $[=\log$ 10 (force $\mathrm{mg}$ )]. $B$ and $C$, Thresholds of neurons in cortical bands with inputs from the overlap (OVERLAP), autonomous ulnar (ULNAR), and autonomous median ( $M E D I A N)$ glabrous strips as a function of relative area $(B)$ or width (C) of these bands. Thresholds are shown for normal, median section, and ulnar-radial section monkeys. $M E$ $D I A N$ thresholds for the MEDIAN SECTION monkeys, and ULNAR thresholds for the UINAR-RADIAL $S E C T I O N$ monkeys were not measurable due to denervation of these skin strips. Note that following median section, thresholds not significantly different from normal were associated with small increases in areas and widths of bands. In contrast, following ulnar-radial section, thresholds decreased in association with larger increases in the areas and widths of bands.
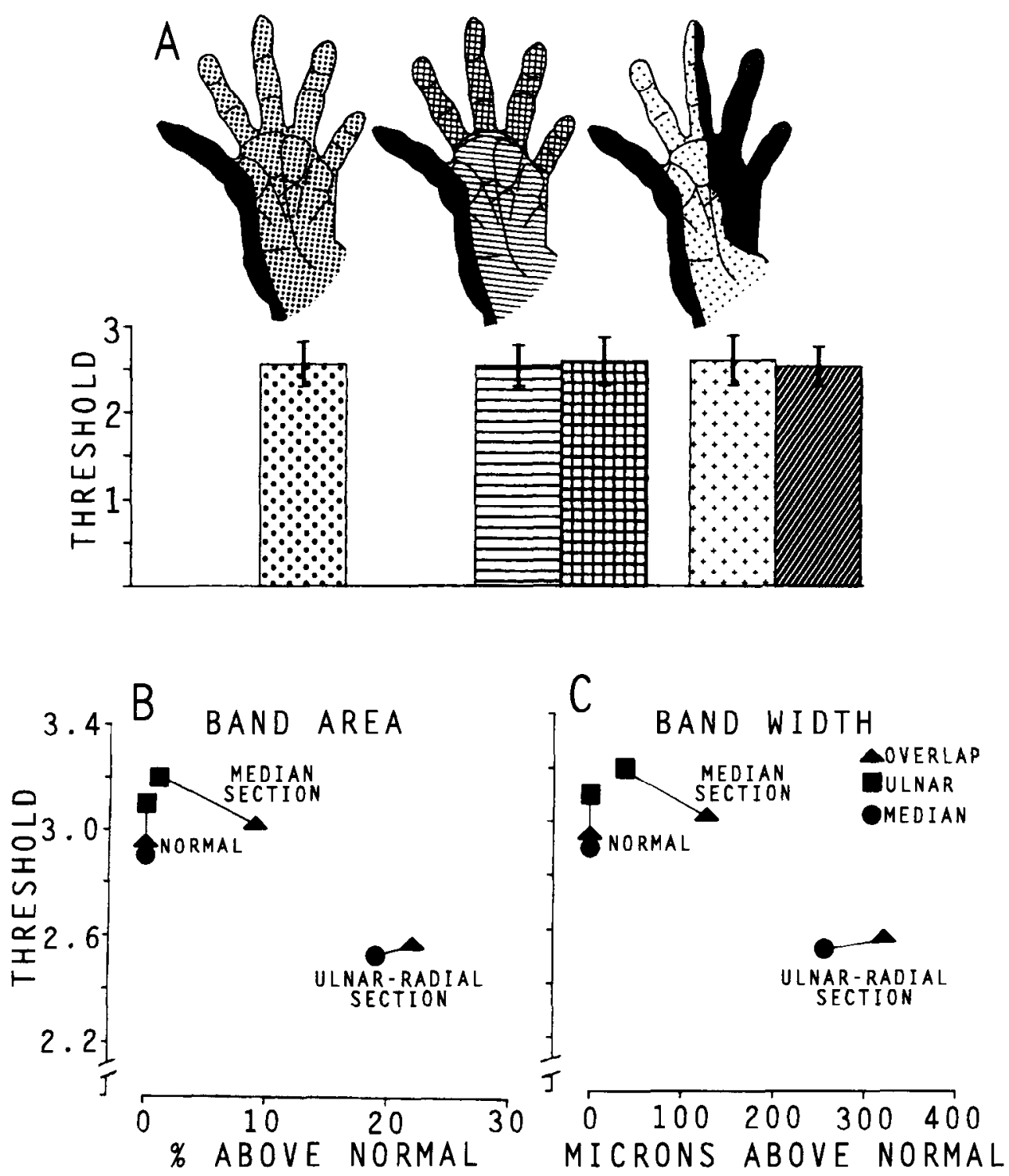

were specific to glabrous skin; however, a mean of $2.7 \%$ of recording sites had a "mixed" field extending across both glabrous and hairy skin. Since similar small percentages of "mixed" fields were seen after median section $(3.1 \%)$ and in normal monkeys $(2.8 \%)$, ulnar-radial section did not appear to alter glabrous-hairy specificity.

\section{Cortical activation reflected across multiple recording sites}

\section{Somatotopic and nerve related organization}

Following ulnar-radial section, the hand map consisted of a continuous glabrous representation (Fig. $4 A-D$ ). Other than a few scattered penetrations with hairy fields on D3 and the handwrist region, the maps had virtually no hairy representation. Palmar pad representations were mainly located caudally, with the representation of P1-TH laterally, PH medially, and P3-4-I and $\mathrm{P} 2$ in between (Figs. 3, Row A; $4 A-D$ ). The main representations of glabrous digits 1-4 were located rostrally, in a similar lateral to medial sequence (Fig. 3, Row B). Consequently, the main palm and digit representations were in register caudorostrally (e.g., Fig. 3, Rows C-E). In addition to these main palm and digit representations, less predictable representations of different pads were located mediorostrally in three of four monkeys (Fig. $4 B-D$ ), and small digit representations were sometimes separated from the main digit representations (e.g., D1 and D3, Fig. 4B,C).

Following ulnar-radial section, the innervated skin consisted of the autonomous median and overlap skin strips. By relating the receptive field defined at each cortical recording site to these strips, it was possible to project these strips onto the cortical maps. Following ulnar-radial section, the autonomous median representation occupied a lateral, rostrocaudally elongated band (Fig. 5). In two monkeys, there was a further small patchlike representation of this skin medially (Fig. 5, cases 86-59 and 86$18 \mathrm{~A})$. The overlap skin representation occupied a rostrocaudal band between the representation of the autonomous median band, laterally, and the wrist, medially (Fig. 5).

The organization after ulnar-radial section resembled normal organization in that the glabrous representation occupied a continuous block of the map, and normal somatotopic organization was seen across much of this block (e.g., Fig. 4). The main differences after ulnar-radial section involved (1) the lack of hairy and ulnar glabrous skin representations (Fig. 4); (2) the 
appearance of small, less predictable pad or digit representations beside the main representations (e.g., see above); (3) a lateral expansion of the autonomous median skin band (Fig. 5); and (4) a medial expansion of the overlap skin band (Fig. 5).

Postnatal ulnar-radial section resulted in organization that showed both similarities and differences with the organization seen after median section. The main similarity was that the glabrous representation occupied a continuous area across which similar receptive field progressions were seen for skin regions that retained innervation (Fig. 4). The main differences involved findings that after ulnar-radial section (1) the hairy representation was lost, whereas this representation was abnormally large after median section (Fig. 4); (2) there were rostromedial abnormalities in the locations of palmar pad representations that were not seen after median section (Fig. 4); (3) thc autonomous median skin band expanded laterally, whereas after median section this band was lost (Fig. 5); and (4) the overlap skin band expanded medially (Fig. 5).

\section{Size measurements}

Total hand map. Following ulnar-radial section, the hand map occupied a mean cortical area of $3.18 \mathrm{~mm}^{2}$. This area did not differ from the mean area of the hand map in normal $\left(3.64 \mathrm{~mm}^{2}\right.$; $t[5]=1.28, p=0.25)$ or median-sectioned $\left(3.75 \mathrm{~mm}^{2} ; t[5]=\right.$ $1.17, p=0.29)$ monkeys.

Hairy representations. Following ulnar-radial section, the few hairy fields contributed to a calculated mean area of less than $1 \%$ of the map (Fig. $6 \mathrm{C}$ ). This virtual zero area contrasts with the large hairy representations in normal $(33 \%)$ and median sectioned (44\%) monkeys (Fig. 6A,B).

Glabrous nerve-related representations. Following ulnar-radial section, the sizes of the cortical bands representing nerve territories on glabrous skin differed from normal in several major respects. (1) The representation of the autonomous ulnar glabrous skin was lost, whereas this representation normally occupied about $15 \%$ of the map (Fig. $6 A, C$ ). (2) Despite this partial glabrous denervation, the overall glabrous representation increased from $67 \%$ of the map in normal monkeys to $93 \%$ after ulnar-radial section (Fig. $6 A, C ; t[5]=5.13, p=0.004$ ). (3) This overall glabrous enlargement involved increases in both the overlap and autonomous median cortical bands. In normal monkeys, the overlap band occupied $22 \%$ of the map, whereas after ulnar-radial section this band doubled to $44 \%$ of the map (Fig. $6 A, C ; t[5]=7.61, p<0.001$ ). Consistent with this area increase, there was a near doubling of the mean width of this band (i.e., $378 \mu \mathrm{m}$ in normals to $699 \mu \mathrm{m}$ after ulnar-radial section). Similarly, in normal monkcys the autonomous median cortical band occupied $30 \%$ of the map, whereas after ulnarradial section this hand occupied a significantly larger $49 \%$ (Fig. $6 A, C ; t[5]=7.58, p<0.001)$. This corresponded with a $51 \%$ increase in the mean width of this band (normal $=499 \mu \mathrm{m}$; ulnar-radial injury $=755 \mu \mathrm{m}$ ). These findings clearly indicate that the cortical representation of skin strips innervated by the median nerve expanded after ulnar-radial injury.

Ulnar-radial section resulted in different changes in the sizes of nerve-related cortical bands than median nerve section. Following median section, the overall glabrous representation occupied $47 \%$ of the map, whereas this increased to $93 \%$ after ulnar-radial section (Fig. $6 B, C ; t[5]=11.52, p<0.001$ ). Related to this change in overall glabrous representation were obvious changes in the glabrous skin nerve bands. (1) The autonomous median band was lost after median section, whereas this band

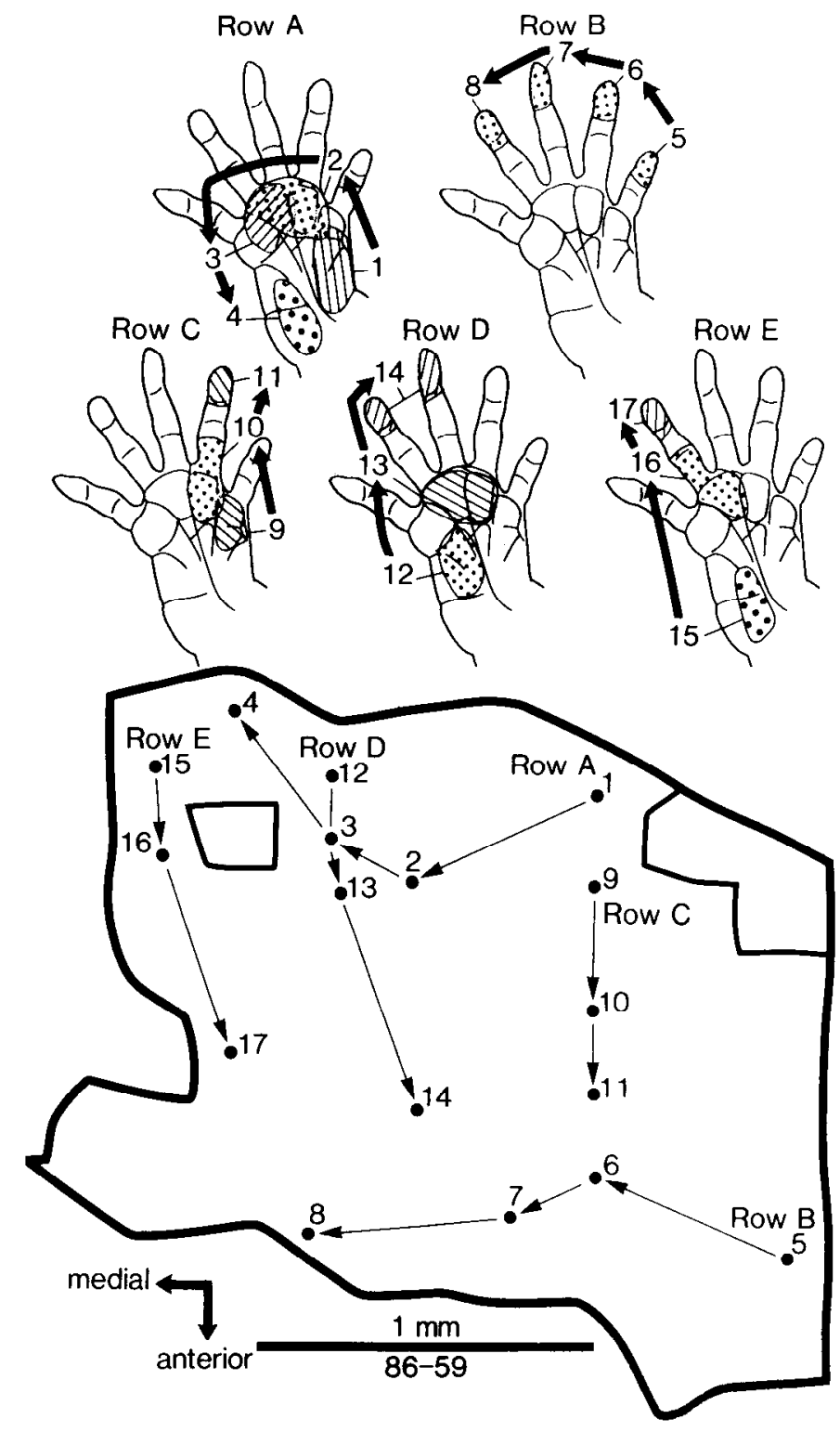

Figure 3. Examples of receptive field size and of somatotopic progressions of receptive fields after ulnar-radial nerve section. There was a rough proximodistal gradient in receptive field size, with larger fields tending to be on palmar pads and smaller fields on distal digits. Recording sites moving along the lateromedial axis of the hand map correspond to receptive field shifts along the radial-ulnar axis of the hand (Rows $A, B$ ), whereas recording sites moving along the posterior-anterior cortical axis correspond to receptive field shifts along the proximodistal axis of the hand (Rows $C-E$ ).

occupied $49 \%$ of the map after ulnar-radial section (Fig. 6B,C). (2) The representation of the autonomous ulnar glabrous skin occupied $16 \%$ of the map after median section, but was lost after ulnar-radial section (Fig. 6B,C). (3) After median section, the overlap skin band occupied $31 \%$ of the map, whereas after ulnar-radial section this band increased to $44 \%$ of the map (Fig. $6 B, C ; t[5]=4.07, p=0.009)$. This enlargement was associated with a $38 \%$ increase in mean width of this band (median section $=505 \mu \mathrm{m}$, ulnar-radial section $=699 \mu \mathrm{m}$ ). From these findings, it is clear that changes in the size of nerve-related cortical bands are dependent on the nerve(s) that are injured and that remain intact. 
Figure 4. Cortical area 3b maps of the hand showing the somatotopic organization of representations of glabrous (white) and hairy (hatched) parts of the hand. Areas with high-threshold inputs are shown in black. Maps are from four monkeys reared after ulnar-radial section $(A-D)$, a normal monkey $(E)$, and a monkey reared after median section $(F)$. The $F Q$ representation was not considered as part of the hand map but is adjacent to the map in most monkeys. See Results for detailed comparisons of these maps. Abbreviations are as in Figure 1. Scale bars, $1 \mathrm{~mm}$.

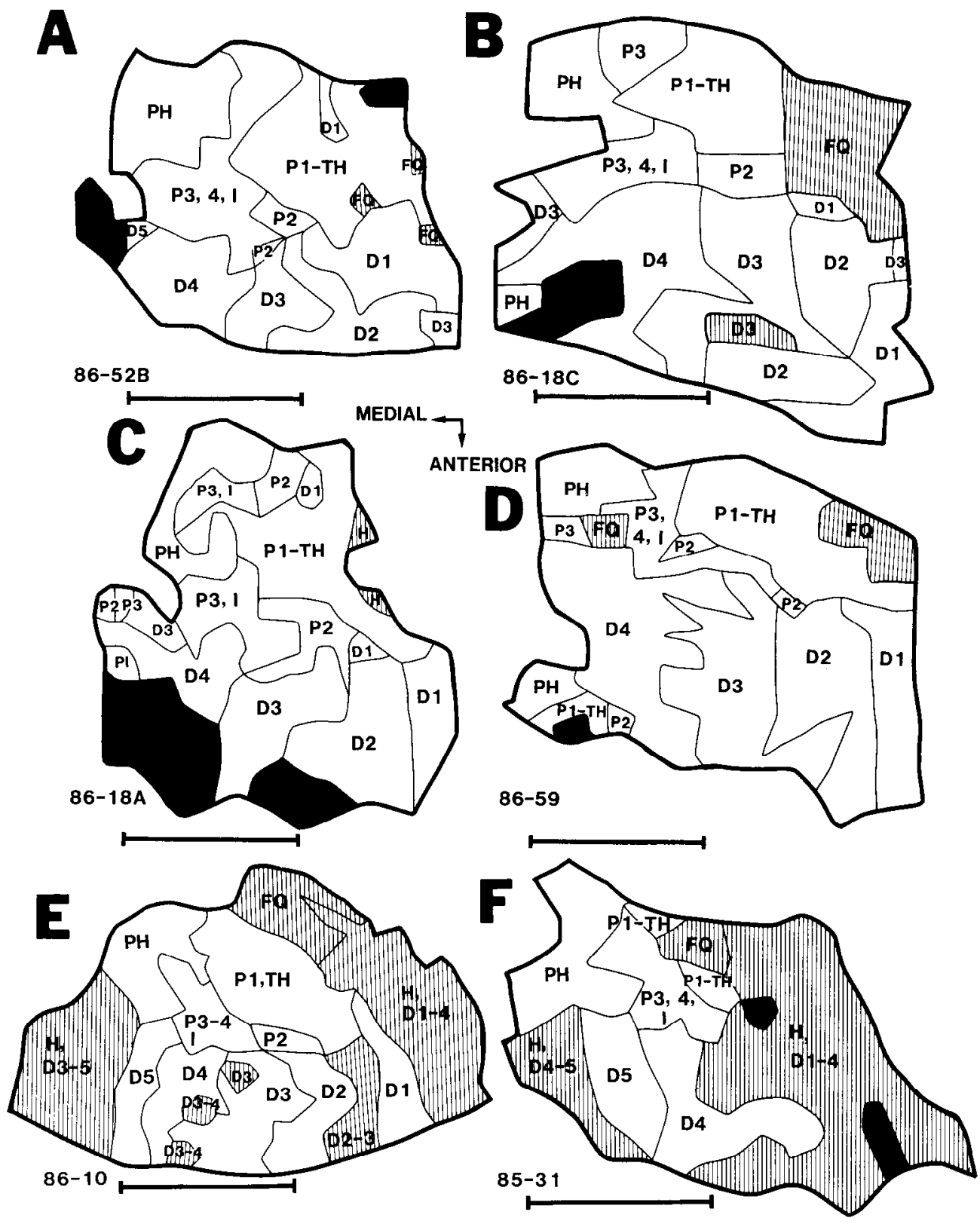

\section{Cortical variability}

The features that accounted for most of the individual variability after ulnar-radial section involved properties of spatial patterning, including representation: shapes (e.g., compare D4 in Fig. 4A-D), sizes (e.g., Fig. 6; mean areas of palmar pad and digit representations were small with coefficients of variation of about 50\%), and interfacings (e.g., compare adjacencies of $\mathrm{PH}$ and $\mathrm{P} 1-\mathrm{TH}$ in Fig. 4A-D). Although these same properties account for most cortical map variability in normal and mediansectioned monkeys (Wall et al., 1992), it is clear that the degree of reorganization in monkeys reared after ulnar-radial section is beyond the range of individual variability seen after the other rearing conditions (Figs. 4, 5).

\section{Relationships between threshold and cortical magnification} As described above, the thresholds for both the overlap and autonomous median strips in monkeys with ulnar-radial section were significantly lower than the analogous thresholds in normal monkeys. These threshold decreases were associated with respective increases of $22 \%$ in arca and $321 \mu \mathrm{m}$ in width for the overlap band, and $19 \%$ in area and $256 \mu \mathrm{m}$ in width for the autonomous median band (Fig. $2 B, C$ ). In contrast, after median section there was no significant difference from normal for the autonomous ulnar thresholds, and the cortical band area and width measures for this strip also showed nonsignificant differences above normal of, respectively, $1 \%$ in area and $37 \mu \mathrm{m}$ in width (Fig. 2B,C). Similarly, the overlap strip thresholds in normal and median-section monkeys were not significantly different, and the corresponding band area and width measures indicated only modest differences from normal of, respectively, $9 \%$ in area and $127 \mu \mathrm{m}$ in width (Fig. 2B,C). Taken together, these results suggest a relationship between increased cortical magnification and decreased cortical tactile thresholds; however, some minimal magnification change appears necessary before thresholds are lowered. The present data suggest that this 


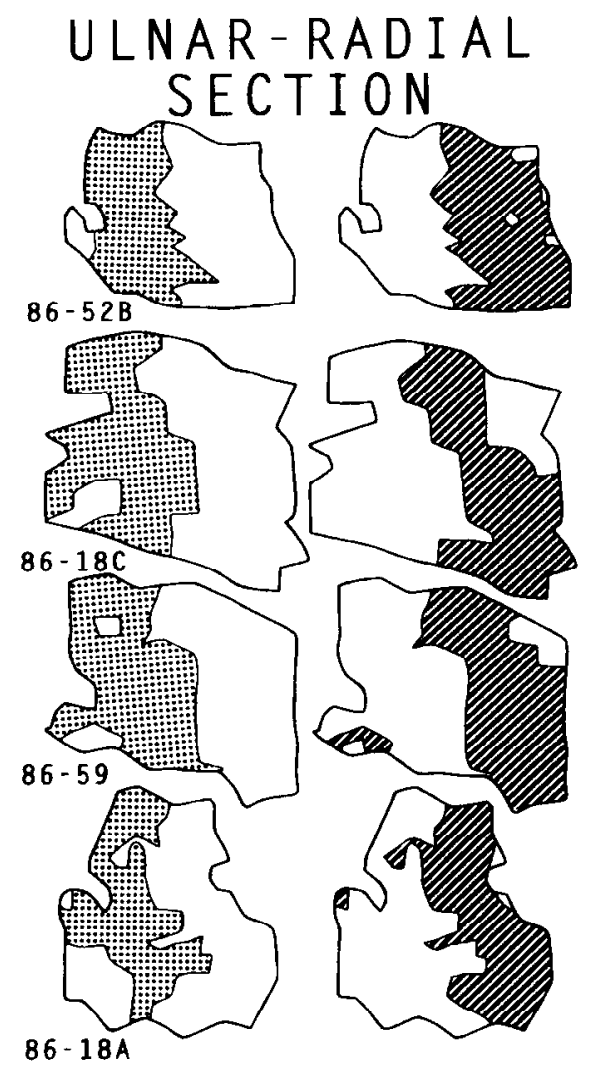

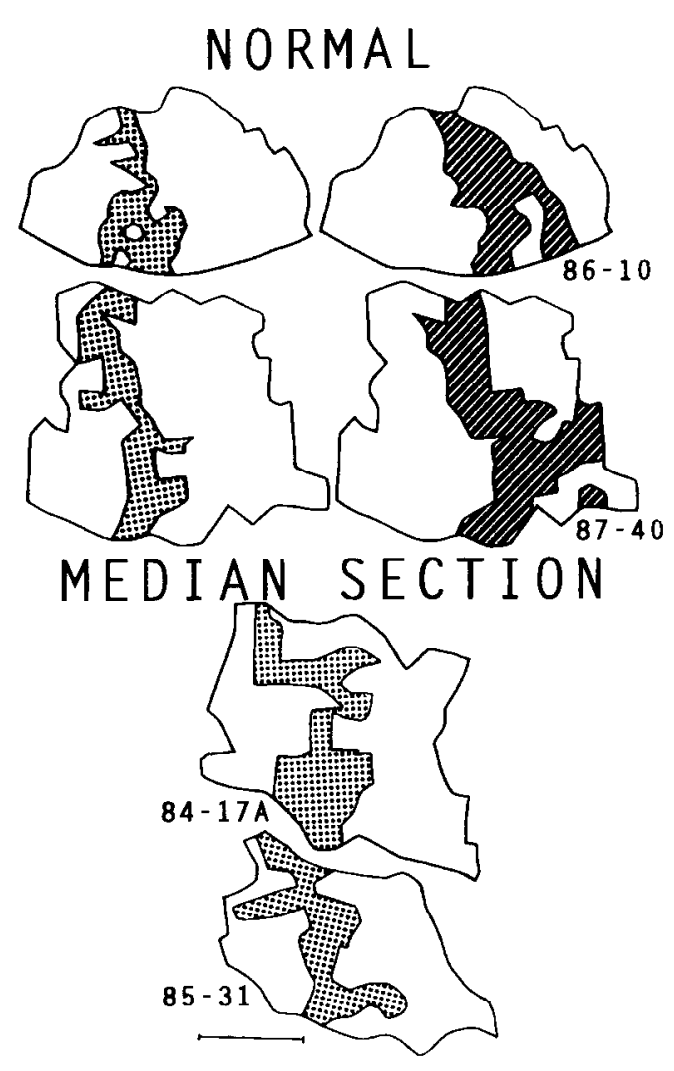

Figure 5. Hand maps showing bandlike aggregates of cortical neurons that were activated by inputs from the overlap (stippling) and autonomous median (hatching) skin strips. Maps are from four monkeys with ulnar-radial nerve section, two normal monkeys, and two monkeys with median nerve section. Interanimal variability can be seen by comparing the analogous aggregation pattern across monkeys in each group. Due to median nerve injury, no band for the autonomous median strip exists in monkeys with median section. Note the lateral and medial expansions of the respective autonomous median and overlap bands in monkeys reared after ulnar-radial section as compared to monkeys in the other groups. Medial, left; anterior, down. Scale bar, $1 \mathrm{~mm}$. minimal level is above area increases of $9 \%$ and width increases of $127 \mu \mathrm{m}$, that is, the largest magnification changes seen without accompanying threshold changes, but at or below area increases of $19 \%$ and width increases of $256 \mu \mathrm{m}$, that is, the smallest magnification changes seen that had accompanying threshold changes.

\section{Discussion}

The postnatal sensory histories of monkeys reared with one, two, or three hand nerves clearly differed in terms of peripheral innervation. Despite this difference, some cortical features underwent little or no apparent change. These features include the (1) adequacy of cutaneous stimuli to evoke responses from neurons at most cortical sites, (2) size and glabrous-hairy specificity of receptive fields, (3) receptive field progressions across localized parts of the hand map, and (4) overall size of the hand map.

In contrast, other cortical features clearly changed. First, there were significant alterations in the location, size, shape, and somatotopic interfacing of representations. Second, under certain conditions there were decreases in the cortical thresholds to cutaneous inputs. Finally, the delineation of the glabrous innervation territories of the hand ncrves and of the corresponding aggregates of cortical neurons that are dominantly activated by low-threshold inputs from these territories clearly indicates that these nerve dominance aggregates change after postnatal nerve injury.

The changes in monkeys reared with one nerve provide support for the conclusions on somatotopic changes discussed in the preceding article (Wall et al., 1992). The somatotopic reorganization seen in the present study is also consistent with previous findings of cortical somatotopic changes following early peripheral injury in rats, cats, and raccoons (e.g., Killackey et al., 1978; Kalaska and Pomeranz, 1979; Kelahan et al., 1981; Simons et al., 1984; Waite, 1984; Wall and Cusick, 1986). As discussed below, the novel findings in the present study derive from the results regarding changes in nerve dominance aggregates and neuronal thresholds.

\section{Nerve dominance aggregates and their modification after postnatal nerve injury}

When the cortical sampling procedures used in the present study were applied to normal monkeys, low-threshold mechanoreceptor inputs from all parts of the hand were represented in the hand map of each monkey (Wall et al., 1992). Given this normal comprehensiveness in representation, it was possible to use cortical receptive field composites to estimate innervated and denervated skin regions on the hand after nerve injury. This information, in turn, was used to estimate the innervation territories of the intact and injured nerves. The innervation changes in the present study are consistent with the low-threshold innervation territories of the hand nerves as determined from nerve mapping experiments in normal monkeys (Huerta and Wall, 1987; Wall, 1990, unpublished observations), and with residual tactile sensitivity tests in patients with hand nerve injuries (e.g., Pollock and Davis, 1933; Hallin et al., 1981; Mackel et al., 1983a,b, 1985; Hunter et al., 1990). The close similarity in innervation territories as estimated in the present experiments and the normal nerve mapping experiments further suggests there was no major sprouting of intact low-threshold mechanoreceptor fibers into denervated skin after postnatal nerve injury.

Given the innervation territories, it was possible to relate a 


\section{A. NORMAL}
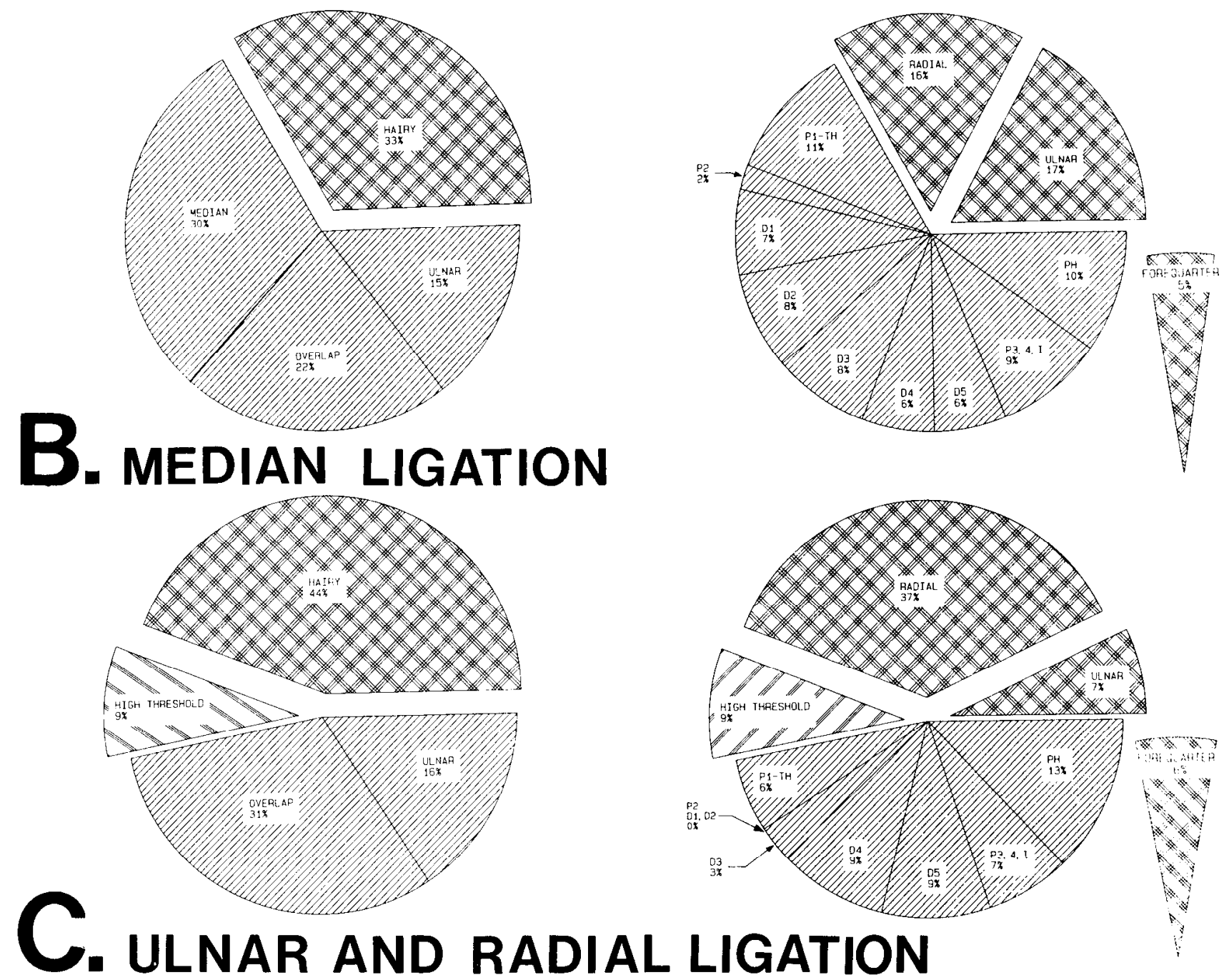

G. ULNAR AND RADIAL LIGATION

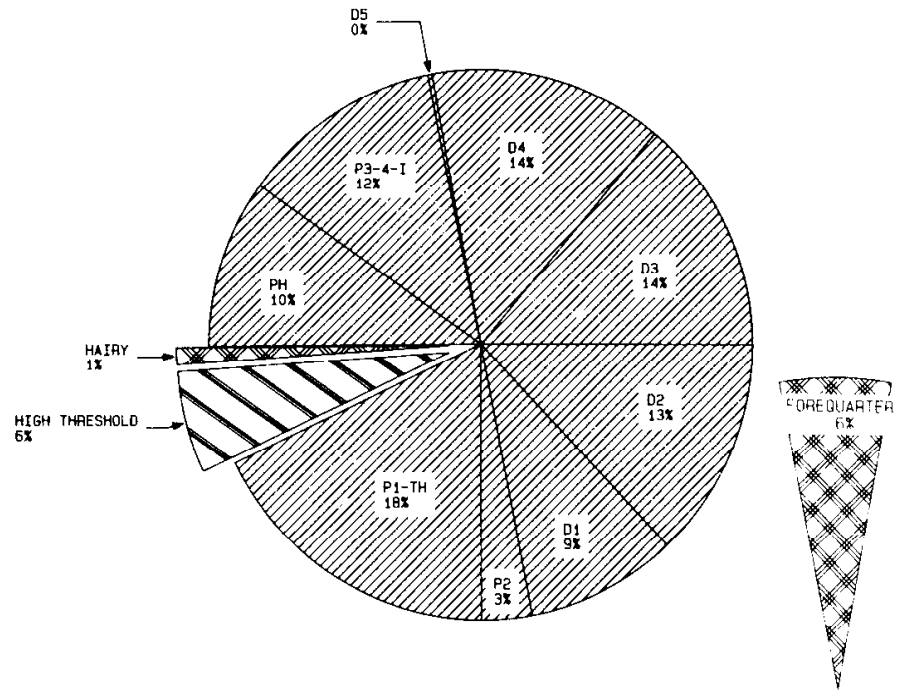

Figure 6. Mean cortical areas activated by inputs from parts of the hand following rearing under normal $(A)$, median nerve section and ligation $(B)$, and ulnar-radial nerve section and ligation (C) conditions. Areas with glabrous (hatching), hairy (cross-hatching), and high-threshold (stripes) in puts are distinguished. Left column, Area with glabrous inputs is subdivided into representations of the autonomous median nerve strip (MEDIAN), the autonomous ulnar nerve strip ( $U L N A R)$, and the median and ulnar nerve overlap strip $(O V E R L A P)$. Right column, Area with glabrous inputs is subdivided into representations of different somatotopic parts, and area with hairy inputs is subdivided into radial and ulnar nerve representations. Note that following ulnar-radial injury, the cortical representations of skin zones innervated by the intact median nerve expand to fill almost the entire hand map. 

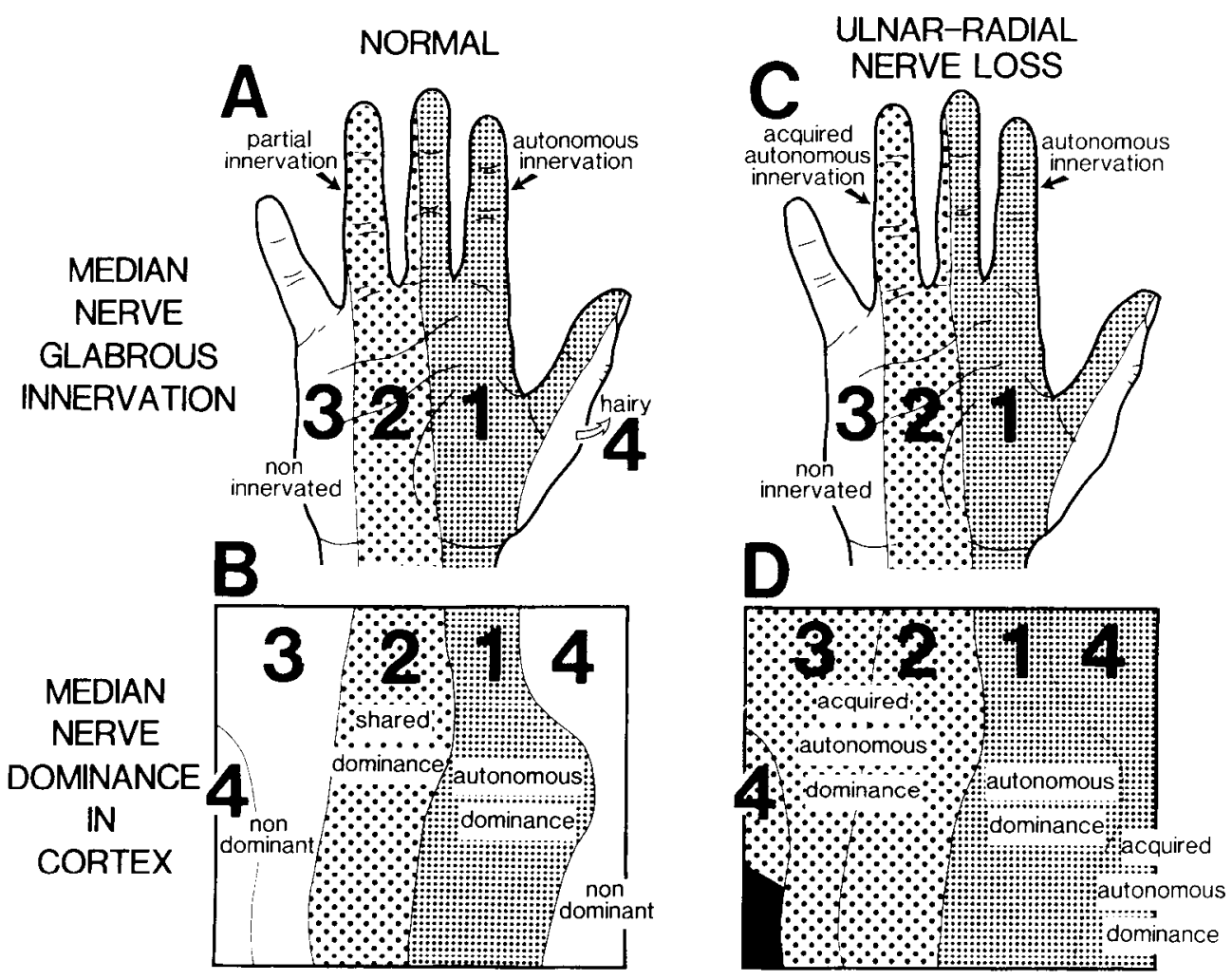

Figure 7. Schematic summary of peripheral innervation and cortical aggregation of median nerve inputs. $A$ and $B$ summarize normal peripheral-cortical relationships, whereas $C$ and $D$ summarize peripheral-cortical relationships in monkeys that, due to ulnar-radial nerve injury, were raised with only a median nerve. $A$, In normal monkeys, the median nerve autonomously innervates the radial glabrous hand $(l)$, and innervates the midhand in overlapping fashion with the ulnar nerve (2). $B$, In cortex, low-threshold mechanoreceptors in these skin strips normally provide dominant inputs to rostrocaudally oriented bands in the hand map (1-2). C. After ulnar-radial nerve section, peripheral innervation by low-threshold median nerve fibers is similar to normal $(I-2)$. $D$. In contrast, in the cortex low-threshold inputs from the median innervated skin become dominant inputs to bands that are mediolaterally expanded into adjacent "deprived" ulnar and radial nerve bands.

low-threshold glabrous receptive field directly to the nerve(s) innervating that ficld. Bascd on the present results, Figure 7, $A$ and $B$, schematically illustrates the relationship of a hand nerve innervation territory and its cortical dominance aggregate in a normally reared monkey using, as an example, low-threshold inputs from the median nerve. The glabrous hand can be viewed as a continuous sheet that comprises three differentially innervated strips. Low-threshold fibers of the median nerve normally provide (1) autonomous innervation to a radial strip (Fig. $7 A$, $\# 1$ ), (2) overlapping innervation with the ulnar nerve to a second strip (Fig. $7 A$, \#2), and (3) no innervation to a third strip (Fig. $7 A$, \#3). In cortex, low-threshold median nerve inputs normally (1) provide dominant input to a rostrocaudally oriented aggregate of cortical neurons representing the autonomous median skin (Fig. 7B, \#1); (2) provide, in an overlapping fashion with ulnar nerve inputs, partial dominant input to a second rostrocaudal aggregate (Fig. $7 B, \# 2$ ); and (3) are not functionally dominant in cortical aggregates relating to other glabrous or hairy representations (Fig. 7B, \#3-4). Thus, in normal monkeys, lowthreshold median nerve inputs provide a range of functional input dominances to cortical neurons in identifiable sectors of the hand map.

The above concept of a projection from a region of a peripheral sensory field to the CNS via a nerve, and of subsequent normal focusing of dominant inputs from this nerve onto spatially organized aggregates of cortical neurons, has only recently been applied to the hand system of primates (Wall, 1990; Wall et al., 1990). However, a similar concept of normal central dominance has been recognized for other systems including, for example, cortical representations of paw nerves in rodents (Wall and Cusick, 1984), and ocular (or eye nerve) dominance columns in the visual system (e.g., Hubel et al., 1977).

The potential for modification of these functional nerve dom- inance aggregates was clearly demonstrated by the results from monkeys reared with only a median nerve. With this rearing, low-threshold median nerve inputs (1) continue to provide autonomous innervation to the normal median autonomous skin (Fig. 7C, \#1), (2) become autonomous inputs from the overlap skin that is normally only partially innervated by median inputs (Fig. $7 C$, \#2), and (3) do not sprout to any major extent into skin regions that are normally not innervated by median inputs (Fig. 7C, \#3; see also above discussion). Thus, intact median nerve inputs retain or acquire autonomy in different skin regions, but do not significantly increase their overall innervation area on the hand.

This peripheral innervation, in turn, results in a cortical pattern of median nerve dominance that is different from that seen in normal monkeys (e.g., Fig. 7D). Comprising this pattern is an aggregate of cortical neurons that (1) retains dominant activation by inputs from the normal autonomous median territory (Fig. 7D, \#1); (2) normally receives overlapping input from the median and ulnar nerves but that, due to ulnar injury, becomes autonomously dominated by median inputs (Fig. $7 D$, \#2); (3) is normally not functionally activated by median nerve inputs but that acquires dominant inputs from overlap skin regions that, due to ulnar injury, become autonomously innervated by median nerve inputs (Fig. $7 D, \# 3$ and left \#4); and (4) is normally not activated by median nerve inputs but that acquires dominant inputs from skin regions that are normally autonomously innervated by the median nerve (Fig. $7 D$, right \#4). These changes appear to be due to both peripheral and central mechanisms. For example, partial denervation of the overlap skin (e.g., Fig. $7 C, \# 2$ ), by default, leaves median inputs as the autonomous source of inputs to the overlap cortical band. Thus, some degree of acquired cortical dominance is due to this "default" peripheral mechanism (e.g., Fig. 7D, \#2). In contrast, 
acquired median nerve dominance in cortical aggregates normally dominated by ulnar and radial nerve inputs must be due to central mechanisms (e.g., Fig. 7D, \#3,4).

The above view suggests that a hand nerve is capable of becoming the dominant source of input to a variably sized cortical space. This view resembles present conceptualizations of ocular dominance column development in the primary visual cortex (e.g., Hubel et al., 1977). Of particular relevance, studies of animals reared with different visual histories show that inputs from the two eyes compete for cortical space during the early postnatal period; consequently, monocular deprivation conditions that provide advantages to one eye result in abnormally large functional columns for that eye (e.g., Hubel et al., 1977; Des Rosiers et al., 1978; LeVay et al., 1978; Shatz and Stryker, 1978). The present results suggest that analogous principles may apply to the postnatal development of hand nerve dominance zones in the somatosensory system.

\section{Changes in cortical threshold and magnification}

Mean glabrous thresholds in monkeys reared with one nerve were lower than the thresholds in normal monkeys and monkeys reared with two nerves. This result does not appear to be easily explained by peripheral factors but, rather, appears to reflect some degree of central alteration that produces a lowering of cortical thresholds that, on average, are normally set close to or slightly above the lowest range of normal peripheral thresholds. Several observations are consistent with this view. (1) The mean cortical neuronal threshold after rearing with only the median nerve [e.g., 2.60 or about $0.39 \mathrm{mN}$ (milliNewtons)] closely approximates the lower range of normal glabrous primary afferent thresholds from the hand (e.g., about 0.10-0.70 mN; Iggo, 1963; Johansson et al., 1980; Mackel et al., 1983a, 1985; LaMotte and Whitehouse, 1986). In contrast, although the lower portions of the distributions of normal cortical and peripheral thresholds overlap (e.g., cortical, about $0.05-0.67 \mathrm{mN}$; peripheral, $0.10-$ $0.70 \mathrm{mN}$ ), when averaged across the entire hand representation the overall normal mean cortical threshold (e.g., 2.98 or about $0.95 \mathrm{mN}$ ) is slightly above the lower range of normal peripheral thresholds. Thus, following ulnar-radial injury, mean cortical thresholds more closely approximate the lower limits of the peripheral afferents. (2) Following rearing with only the median nerve, thresholds were lowered a similar degree for inputs from the autonomous median and overlap skin. Since the density of lost and surviving inputs would be different in these territories, lowering of cortical thresholds to a similar degree is not parsimoniously explained by simple alterations in the density of peripheral receptors. (3) Following rearing with only the median nerve, thresholds for inputs from the overlap territory were lower than normal, whereas following rearing with the ulnar and radial nerves, thresholds for inputs from this skin did not change from normal. Since both rearing conditions have a qualitatively similar effect on the overlap skin, that is, partial survival (or loss) of inputs, it does not appear that lowered cortical thresholds after ulnar-radial section can be parsimoniously explained by peripheral changes. Consistent with this view, thresholds of largediameter mechanoreceptor fibers innervating glabrous skin around denervated, reinnervated, or grafted skin regions are either normal or above normal, rather than decreased (Terzis and Dykes, 1980; Mackel et al., 1983a,b, 1985; Dykes et al., 1984; Ochs et al., 1989). (4) Finally, the decreases in thresholds of cortical neurons appear related to cortical magnification changes that reach some minimal degree of expansion. This correlation is hard to explain solely on the basis of changes in peripheral factors. Taken together, the above findings suggest that cortical changes after postnatal nerve injury involve central changes in input dominance that, under some conditions, reset cutaneous activation thresholds.

\section{References}

Des Rosiers MH, Sakurada O, Jehle J, Shinohara M, Kennedy C, Sokoloff L (1978) Functional plasticity in the immature striate cortex of the monkey shown by the $\left[{ }^{14} \mathrm{C}\right]$ deoxyglucose method. Science 200 : 447-449.

Dykes RW, Terzis JK, Turnbull BG (1984) Properties of mechanoreceptive fibres serving skin grafts transferred to the hands of adult baboons (Papio anubis). J Physiol (Lond) 357:1-22.

Hallin RG, Wiesenfeld Z, Lindblom U (1981) Neurophysiological studies on patients with sutured median nerves: faulty sensory localization after nerve regeneration and its physiological correlates. Exp Neurol 73:90-106.

Iubel DII, Wiesel TN, LeVay S (1977) Plasticity of ocular dominance columns in monkey striate cortex. Philos Tran R Soc Lond [Biol] 278:377-409

Huerta MF, Wall JT (1987) The functional territory of the primate median nerve in the hand skin and cortical map of the hand. Soc Neurosci Abstr 13:250.

Hunter JM, Schneider LH, Mackin EJ, Callahan AD (1990) Rehabilitation of the hand, $3 \mathrm{~d}$ ed. St. Louis: Mosby.

Iggo A (1963) An electrophysiological analysis of afferent fibres in primate skin. Acta Neuroveg 24:225-240.

Johansson RS, Vallbo AB, Westling G (1980) Thresholds of mechanosensitive afferents in the human hand as measured with von Frey hairs. Brain Res 184:343-351.

Kalaska J, Pomeranz B (1979) Chronic paw denervation causes an age-dependent appearance of novel responses from forearm in "paw cortex" of kittens and adult cats. J Neurophysiol 42:618-633.

Kelahan AM, Ray RH, Carson LV, Massey CE, Doetsch GS (1981) Functional reorganization of adult raccoon somatosensory cerebral cortex following neonatal digit amputation. Brain Res 223:151-159.

Killackey HP, Ivy GO, Cunningham TJ (1978) Anomalous organization of SMI somatotopic map consequent to vibrissae removal in the newborn rat. Brain Res 155:136-140.

LaMotte RH, Whitehouse J (1986) Tactile detection of a dot on a smooth surface: peripheral neural events. J Neurophysiol 56:11091128 .

LeVay S, Stryker MF, Shatz CJ (1978) Ocular dominance columns and their development in layer IV of the cat's visual cortex: a quantitative study. J Comp Neurol 179:223-244.

Mackel R, Kunesch E, Waldhor F, Struppler A (1983a) Reinnervation of mechanoreceptors in the human glabrous skin following peripheral nerve repair. Brain Res 268:49-65.

Mackel R, Brink EE, Wittkowsky G (1983b) Transitional properties of afferents reinnervating mechanoreceptors in the human glabrous skin. Brain Res 276:339-343.

Mackel R, Brink EE, Wittkowsky G (1985) Properties of cutaneous mechanosensitive afferents during the early stages of regeneration in man. Brain Res 329:49-69.

Ochs G, Schenk M, Struppler A (1989) Painful dysaesthesias following peripheral nerve injury: a clinical and electrophysiological study. Brain Res 496:228-240.

Pollock LJ, Davis L (1933) Peripheral nerve injuries. New York: Hoeber.

Shatz CJ, Stryker MP (1978) Ocular dominance in layer IV of the cat's visual cortex and the effects of monocular deprivation. J Physiol (Lond) 281:267-283.

Simons DJ, Durham D, Woolsey TA (1984) Functional organization of mouse and rat SmI barrel cortex following vibrissal damage on different postnatal days. Somatosens Res 1:207-245.

Terzis JK, Dykes RW (1980) Reinnervation of glabrous skin in baboons: properties of cutaneous mechanoreceptors subsequent to nerve transection. J Neurophysiol 44:1214-1225.

Waite PME (1984) Rearrangement of neuronal responses in the trigeminal system of the rat following peripheral nerve section. J Physiol (Lond) 352:425-445.

Wall JT (1990) Nerve dominance columns in the primate primary somatosensory (area 3b) cortex. Soc Neurosci Abstr 16:228. 
Wall JT, Cusick CG (1984) Cutancous responsiveness in primary somatosensory (S-I) hindpaw cortex before and after partial hindpaw deafferentation in adult rats. J Neurosci 4:1499-1515.

Wall JT, Cusick CG (1986) The representation of peripheral nerve inputs in the S-I hindpaw cortex of rats raised with incompletely innervated hindpaws. J Neurosci 6:1129-1147.

Wall JT, Florence SL, Huerta MF, Kaas JH (1990) Functional and morphological aggregation in the somatosensory system of primates and its relevance for central reorganization after peripheral injury. In: Recent achievements in restorative neurology, Vol 3, altered sensation and pain (Dimitrijevic MR, Wall PD, Lindblom U, eds), pp 165-180. New York: Karger.

Wall JT, Huerta MF, Kaas JH (1992) Changes in the cortical map of the hand following postnatal median nerve injury in monkeys: modification of somatotopic aggregates. J Neurosci 12:3445-3455. 